\title{
Capsule commentary on Geller et al., National estimates of emergency department visits for antibiotic adverse events among adults-United States, 2011-2015
}

\author{
Janice Blanchard, MD, $P h D$ \\ Department of Emergency Medicine, George Washington University, Washington, DC, USA.
}

$\mathrm{J}$ Gen Intern Med 33(7):1140

DOI: $10.1007 / \mathrm{s} 11606-018-4474-\mathrm{y}$

(c) Society of General Internal Medicine 2018

$\mathrm{G}$ eller et al. present estimates of the rate, number, and clinical characteristics of adverse events (AEs) related to antibiotics using public health surveillance and dispensed prescription data. ${ }^{1}$ Between 2011 and 2015, there were 145,490 ED visits for antibiotic-related AEs. Oral sulfonamides were the most commonly implicated antibiotic class, followed by penicillins and quinolones. Mild allergic reactions were the most common AEs, occurring most often in sulfonamides. ${ }^{1}$

The paper does not explore the number of AEs that resulted in hospitalization, which would have provided greater context about the severity of the events encountered. Interestingly, the authors note that their findings are similar to those of a study completed a decade ago. It would have been helpful for the authors to discuss some of the changes in antibiotic usage that may have occurred during the interval between these two studies. In particular, the increase in the use of certain classes of drugs and the changes in resistance patterns were not discussed.

These findings are particularly salient given the high rate of antibiotic use in the USA, where an average of 22 doses of antibiotics is prescribed per person annually. ${ }^{2}$ The Centers for Disease Control and Prevention estimates that in up to $50 \%$ of cases in which an antibiotic is prescribed, it is used inappropriately. ${ }^{3}$ The authors highlight that a third of ED visits for antibiotic-related adverse events were among adults between the ages of 20-34. As the authors note, this younger population is a group that may be particularly amenable to discussion about the dangers of antibiotic use. ${ }^{1}$ The use of antibiotics is a shared decision made between the provider and the patient with patient expectations for antibiotics often contributing to overuse. Providers may be able to use the data from this study to have more enlightened discussions with patients. This information can also be incorporated into current research efforts that are exploring novel approaches to engage providers in education about antibiotic stewardship, such as through the use of social media. ${ }^{4}$ Although patient-oriented efforts have been less common, ${ }^{5}$ future research should also focus on optimal approaches to educate consumers about antibioticrelated AEs.

Corresponding Author: Janice Blanchard, $M D, P h D$; Department of Emergency Medicine George Washington University, Washington, DC, USA (e-mail:jblanchard@mfa.gwu.edu).

\section{REFERENCES}

1. Geller AI, Lovegrove MC, Shehab N, Hicks LA, Sapiano MRP, Budnitz DS. 2018. National Estimates of Emergency Department Visits for Antibiotic Adverse Events among Adults-United States, 2011-2015. J Gen Intern Med. (SPI 4430)

2. Van Boeckel TP, Gandra S, Ashok A. Global antibiotic consumption 2000 to 2010: an analysis of national pharmaceutical sales data. Lancet Infect Dis. 2014; 14(8):742-750.

3. Centers for Disease Control and Prevention.2013 Antibiotic prescribing and use in hospitals and long-term care. Available at http://www.cdc.gov/ drugresistance/threat-report-2013.

4. Pisano J, Petit N, Barlett A, Bhagat P, Han Z, Lao C, Landon E. Social media as a tool for antimicrobial stewardship. Am J Infect Control. 2016; 44: 1231-1236.

5. Saam M, Huttner B, Harbarth S. World Health Organization. Evaluation of antibiotic awareness campaigns. Available at http://www.who.int/selection_medicines/committees/expert/21/applications/s6_antibiotic_awareness_campaigns.pdf

Published online May 3, 2018 